NASA Contractor Report 195411

AIAA-95-0734

\title{
An Application of a Two-Equation Model of Turbulence to Three Dimensional Chemically Reacting Flows
}

J. Lee

NYMA, Inc.

Engineering Services Division

Brook Park, Ohio

December 1994

Prepared for

Lewis Research Center

Under Contract NAS3-27186

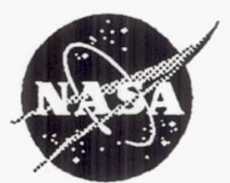

National Aeronautics and

Space Administration 


\title{
An application of a two-equation model of turbulence to three dimensional chemically reacting flows
}

\author{
J. Lee ${ }^{*}$ \\ NYMA Inc. \\ Engineering Services Div \\ NASA Lewis RC Group \\ Brook Park, OH
}

\begin{abstract}
A numerical study of three dimensional chemically reacting and non-reacting flowfields is conducted using a two-equation model of turbulence. A generalized flow solver using an implicit LowerUpper(LU) diagonal decomposition numerical technique and finite-rate chemistry has been coupled with a low-Reynolds number two-equation model of turbulence. This flow solver is then used to study chemically reacting turbulent supersonic flows inside combustors with synergetic fuel injectors. The reacting and nonreacting turbulent combustor solutions obtained are compared with zero-equation turbulence model solutions and with available experimental data. The hydrogen-air chemistry is modeled using a nine-species/eighteenreaction model. A low-Reynolds number $k-\varepsilon$ model was used to model the effect of turbulence because, in general, the low-Reynolds number $k-\varepsilon$ models are easier to numerically implement and are far more general than algebraic models. However, low-Reynolds number $\mathrm{k}-\varepsilon$ models require a much finer near-wall grid resolution than high-Reynolds number models to accurately resolve the near-wall physics. This is especially true in complex flow fields, where the stiff nature of near-wall turbulence must be resolved. Therefore, the limitations imposed by the near-wall characteristics and compressible model corrections need to be evaluated further. The gradient-diffusion hypothesis is used to model the effects of turbulence on the mass diffusion process. The influence of this low-Reynolds number turbulence model on the reacting flowfield predictions was studied parametrically.
\end{abstract}

\section{Nomenclature}

$\begin{array}{ll}\mathrm{A}, \mathrm{B}, \mathrm{C} & \text { Convective Jacobians } \\ \mathrm{D} & \text { Difference Operator } \\ \mathrm{C}_{\varepsilon 1}, \mathrm{C}_{\varepsilon 2} & \text { Turbulence Model Constants, Table 1 } \\ \mathrm{C}_{\mu} & \text { Eddy Viscosity Constant }(=0.09) \\ \mathrm{f}_{\mu} & \text { Wall Damping Function, Eqn } 7 \\ H & \text { Source Vector } \\ \mathrm{h}_{\mathrm{i}} & \text { Enthalpy of } \mathrm{i}^{\text {th }} \text { species } \\ \mathrm{h} & \text { Cell Volume } \\ \mathrm{I} & \text { Identity Vector } \\ \mathrm{k} & \text { Turbulent Kinetic Energy } \\ l & \text { Length Scale, Eqn } 27 \\ \mathrm{M} & \text { Mach Number, }\left(=\mathrm{u} /(\overline{\gamma \mathrm{R} T})^{1 / 2}\right) \\ \mathrm{MW}_{\mathrm{i}} & \text { Molecular Weight of } \mathrm{i}^{\text {th }} \text { Species } \\ \mathrm{M}_{\mathrm{t}} & \text { Turbulent Mach Number }\left(=2 \mathrm{k} /(\gamma \mathrm{RT})^{1 / 2}\right)\end{array}$

\footnotetext{
* Research Engineer, Member AIAA
}

Copyrighto 1995 by the American Institute of Aeronautics and Astronautics, Inc. No copy right is asserted in the United States under Title 17, U. S. code. The Government has a royalty-free license to exercise all rights under the copyright claimed herein for Governmental purposes. All other rights are reserved by the copyright owner.

$\begin{array}{ll}\mathrm{N}_{\mathrm{r}} & \text { Number of Chemical Reactions }(=18) \\ \mathrm{N}_{\mathrm{s}} & \text { Number of Chemical Species }(=9) \\ \mathrm{P}_{\mathrm{k}} & \text { Turbulence Production } \\ \mathrm{Pr} & \text { Prandtl Number } \\ \mathrm{R} & \text { Universal Gas Constant } \\ \mathrm{R}_{\mathrm{t}} & \text { Turbulent Reynolds Number }\left(=\mathrm{k}^{2} / v \varepsilon\right) \\ \mathrm{T} & \text { Temperature } \\ \mathrm{T}_{\mathrm{u}} & \text { Turbulence Intensity } \\ \mathrm{T}_{\mathrm{ijk}} & \text { Source Jacobian } \\ \overline{\mathrm{u}}_{\mathrm{i}}{ }^{\prime \prime} & \text { Mass Averaged Velocity } \\ u_{\mathrm{u}, \mathrm{v}, \mathrm{w}} & \text { Mean Velocity Constants } \\ \mathrm{U}_{\tau} & \text { Friction Velocity }\left(=\left(\tau_{\mathrm{w}} / \mathrm{\rho}\right)^{1 / 2}\right) \\ \mathrm{x}, \mathrm{y}, \mathrm{z} & \text { Coordinates } \\ \mathrm{X}_{\mathrm{i}} & \text { Mole Fraction } \\ \mathrm{y}^{+} & \text {Non-Dimensional Distance } \\ \mathrm{Y}_{\mathrm{i}} & \text { Species Mass Fraction }\end{array}$

Symbols

$\varepsilon \quad$ Specific dissipation

$\delta \quad$ Boundary Layer Thickness 


$\begin{array}{ll}\delta_{\mathrm{ij}} & \text { Kronecker Delta } \\ \gamma & \text { Maximum spectral radii }(=\operatorname{MAX}(\lambda)) \\ \bar{\gamma} & \text { Gas constant } \\ \lambda & \text { Local spectral radii } \\ \Lambda & \text { Low Reynolds number terms } \\ \mu & \text { Viscosity } \\ \mu_{\mathrm{t}} & \text { Eddy Viscosity }\left(=\mathrm{C}_{\mu} \mathrm{f}_{\mu} \mathrm{k}^{2} / \varepsilon\right) \\ \nu & \text { Kinematic Viscosity } \\ \eta, \xi, \zeta & \text { Body fitted coordinate system } \\ \eta_{\mathrm{c}} & \text { Combustion Efficiency } \\ \eta_{\mathrm{m}} & \text { Mixing Efficiency } \\ \bar{\phi}, \text { Phi } & \text { Fuel-Air Equivalence Ratio } \\ \bar{\sigma} & \text { Viscous Diffusion Coefficient, Table 1 } \\ \tau & \text { Shear Stress } \\ \tau_{\mathrm{ij}} & \text { Reynolds Stresses }\end{array}$

Subscripts and superscripts

$\begin{array}{ll}\text { a, b, c } & \text { With respect to the Directions } \\ \text { n } & \text { Pseudo time index } \\ \text { t } & \text { With respect to Turbulence } \\ \text { v } & \text { With respect to Viscous Terms } \\ \wedge & \text { Transformed Variable } \\ \infty & \text { Freestream } \\ 0 & \text { At the inlet }\end{array}$

In order to design a more efficient and reliable propulsion system for high speed vehicles such as the National Aero-Space Plane(NASP) or the High Speed Civil Transport, it is essential to be able to accurately predict the chemically reacting flow field inside the combustors. In particular, a number of physical mechanisms affecting the mixing and combustion must be modeled correctly so that the combustors can be readily analyzed and optimized. A design tool that can be used to study three-dimensional turbulent non-reacting and reacting flow fields in supersonic combustors has been developed and its potential in investigating possible fuelair mixing mechanisms is demonstrated. In this study, we will deal primarily with the analyses of flowfields inside combustors to assess the effectiveness of a $k-\varepsilon$ turbulence model. By comparing numerical predictions with available experimental data, we show that the complex flow features inside of combustors can be reasonable predicted using a typical $\mathrm{k}-\varepsilon$ model of turbulence.

In supersonic flow, low combustor efficiency is a consequence of the low shear-mixing caused by compressibility effects, and the extremely short combustor residence time of the injected fuel. ${ }^{1}$ In an earlier study of the supersonic shear-layer, Brown and Roshko ${ }^{2}$ showed that the spreading rate of a supersonic mixing layer decreases dramatically with increasing freestream Mach number. Therefore, number of investigators have introduced external mixing enhancements into their streamwise injector designs through additional compression/expansion surfaces. Some investigators believe that the initial shear and the vorticity generated by spanwise convolutions ${ }^{3,4}$ and externally generated swirl will produce optimal combustor designs. Therefore, these concepts have been incorporated into the swept-ramp injectors ${ }^{7}$ and swirling nozzle designs. 5,6 Drummond et. al. ${ }^{7}$ and Marble et. al. ${ }^{8}$ proposed that externally generated vorticity be used to generate additional mixing; Drummond ${ }^{7}$ numerically showed that the swept wedge injector, which generates a strong streamwise vorticity, has far superior mixing characteristics than its un-swept counterpart. In the work of Marble et. al., ${ }^{8}$ planar shockwaves were used to enhance the mixing between coflowing circular jets of fuel and air. Marble showed that a jet processed by an oblique shock-wave will produce a strong vortical component due to the interaction between the density differential of fuel-air and the strong pressure gradient across the shock-wave. The effects of this interaction was later numerically demonstrated by Drummond. ${ }^{7}$

Many of the previously discussed design concepts increases flow complexity and makes performance analyses very difficult. One potential method of analyzing the combustor flowfield is to use CFD tools. However, in order to determine the potential effectiveness of a particular combustor design, accurate numerical and physical models are needed. During the past several years, significant progress has been made in the development of new physical models in turbulence and in finite rate chemistry and the model limitations are better understood.

The simplest of the turbulence models assume length scale behaviors and are called zero equation algebraic eddy viscosity models. These models utilize an assumed local equilibrium turbulent scale distribution and the mean shear information to complete the Boussinesq hypotheses necessary to close the averaged Navier-Stokes equations. The models in this class are widely used in computations because of their simplicity. However, the major Achilles heel of these models is the limitation imposed by the equilibrium assumption used in the development of the length scale profiles. In flowfields involving nonequilibrium phenomena, such as separation, sudden removal or addition of pressure gradient, injection, suction, wall temperature gradient and roughness, the predictions made using these models tend to be poor because the required model physics often exceed the equilibrium assumption. ${ }^{9}$ It was previously shown that the simplest turbulence models can yield reasonable combustor flowfield predictions. ${ }^{10}$ However, this work also illustrated the need for a more accurate turbulence model to resolve the performance characteristics needed in design.

The second class of models uses scalar transport equations to model the evolution of the turbulent length and velocity scales of the flowfield and therefore these models are not limited to equilibrium situations. Unfortunately, a majority of the modeling parameters and the near-wall formulations are optimized only for simple flow situations. Therefore, the limitations of these models must be carefully explored in complex flow situations. The most widely used of the two equation eddy viscosity models is the $k-\varepsilon$ model. In this formulation the length scale and the velocity scale needed to determine the eddy 
viscosity are computed from the modeled turbulent kinetic energy and dissipation rate transport equations. The $k-\varepsilon$ model has been used in a wide variety of low Mach number problems. There are, however, several well known $k-\varepsilon$ model deficiencies. A major deficiency of the model is its inability to handle no-slip surfaces. Extensive review of this deficiency and analysis of the various model correction formulations have been conducted by Patel et $\mathrm{al}^{9}$ and Coakley and Huang. ${ }^{11}$ There are two techniques commonly used to resolve this difficulty. The first method replaces the turbulence transport equations in the nearwall regions with a known log-law solution. This is usually known as the high-Reynolds number/wall-function approach. The second method simply modifies the transport equations so that the singular behavior in the near wall region is removed.

In this work, a flow solver with finite rate chemistry model is further extended using a two-equation model of turbulence. Although algebraic turbulence models perform well in simple wall bounded flows, the advantages of using two-equation models in corner flow and shear flow predictions are well documented. Therefore, a lowReynolds number $\mathrm{k}-\varepsilon$ model/solver with dilatation corrections $s^{12,13}$ in three-dimensional form has been developed for combustor simulations. The primary focus of this investigation is to study the influence of the turbulence model on the predictions of supersonic nonreacting and reacting flow fields

\section{Governing Equations}

The conservative form of the three dimensional continuity, momentum, energy, species conservation, and turbulent transport equations were solved in following generalized from:

$$
\frac{\partial Q}{\partial t}+\frac{\partial}{\partial x}\left(E-E_{v}\right)+\frac{\partial}{\partial y}\left(F-F_{v}\right)+\frac{\partial}{\partial z}\left(G-G_{v}\right)=H
$$

where the conservative vector, $\mathrm{Q}$, is defined as:

$$
Q=\left(\rho, \rho u, \rho v, \rho w, \rho E_{t}, \rho Y_{n}\right)^{T}
$$

All of the quantities appearing above are mass $\left(F_{a v r e}{ }^{14}\right)$ averaged, e.g. $\mathrm{u}=\rho u / \bar{\rho}$, and $\mathrm{k}=\rho k / \bar{\rho}$. The density $(\rho)$ is conventionally averaged. The convective and diffusive terms in E,F, and $\mathrm{G}$ are shown in detail by $\mathrm{Yu}$ et. al. ${ }^{15}$ The source vector, $\mathrm{H}$, contains the mass transfer terms in the species transport equations and the production/destruction terms of the turbulent kinetic energy and specific dissipation transport equations.

$$
H=\left(0,0,0,0,0, \dot{\omega}_{n}\right)^{T}
$$

A nine species-eighteen reaction model is employed to model $\mathrm{H}_{2}$-air chemistry. In this model the molecular nitrogen, $\mathrm{N}_{2}$, is assumed to be inert. Therefore, only the remaining eight species continuity equations were numerically solved; the coupled Lower-Upper(LU) diagonal decomposition approach proposed by Shuen and
Yoon ${ }^{17}$ was used. The LU decomposition of the implicit side of the numerics, combined with Symmetric Successive Over Relaxation(SSOR), ${ }^{17}$ reduces the overall implicit numerical procedure to a series of scalar inversions. The mass-averaged species continuity equations and the Navier-Stokes equations were implicitly formulated for numerical efficiency. The implicit coupling of the finite rate source terms was used to reduce the numerical stiffness associated with the chemical time scales that need to be resolved. The turbulent kinetic energy and specific dissipation transport equations were solved decoupled from the mean solver.

\section{I.a Generalized Two Equation Turbulence Model}

In general, there are several types of low-Reynolds number $\mathrm{k}-\varepsilon$ models; the major distinguishing feature of these models is the handling of the singularity that exists in the destruction term of the specific dissipation equation. The most common practice is to use a modified form of the transport equations, where a fictitious dissipation $(\bar{\varepsilon})$ rather than the real dissipation( $(\varepsilon)$ is used. The fictitious dissipation is usually defined as $\bar{\varepsilon}=\varepsilon-\varepsilon_{\text {wall }}$. There are three types of low-Reynolds number $k-\varepsilon$ models. The first type uses flowfield characteristics, such as curvature of the turbulent kinetic energy $\left(\varepsilon_{\text {wall }}=2 v\left(d^{2} k / d y^{2}\right)^{2}\right)$, to satisfy the near wall asymptotic behavior, while avoiding the singularity caused by the no-slip boundary condition. The $k-\varepsilon$ model formulation proposed by Launder and Sharma ${ }^{20}$ is typical of this type of formulation. The second type of low-Reynolds number k- $\varepsilon$ model, proposed by Chien, ${ }^{21}$ uses the wall normal distance $\left(\varepsilon_{\mathrm{wall}}=2 \mathrm{vk} / \mathrm{y}_{\mathrm{n}}{ }^{2}\right)$ and VanDriest type damping to develop the necessary near wall characteristics. The third type of low-Reynolds number formulation does not modify the transport equation; rather, finite near-wall characteristics are used as boundary conditions. The low Reynolds number model proposed by $\mathrm{Shih}^{22}$ is typical of the models that avoid the zero boundary condition and therefore the singularity. All three employ additional wall damping to satisfy near wall physics. In practice, the low-Reynolds number $k-\varepsilon$ models are easier to implement numerically than high Reynolds number models with wall function boundary conditions for complex geometries. However, the low-Reynolds number models also require much higher near wall grid resolution and careful grid strategy.

The two-equation model of turbulence can be written in the generalized strong conservative form of Equation 1, where the conservative vectors are defined as follows:

$$
\begin{gathered}
Q=(\rho k, \rho \varepsilon)^{T} \\
E-E_{v}=\left[\begin{array}{c}
\rho k u-\left(\mu+\frac{\mu_{t}}{\bar{\sigma}_{k}}\right) \frac{\partial_{k}}{\partial x} \\
\rho \varepsilon u-\left(\mu+\frac{\mu_{t}}{\bar{\sigma}_{\varepsilon}}\right) \frac{\partial_{\varepsilon}}{\partial_{x}}
\end{array}\right]
\end{gathered}
$$

and the $F$ and $G$ vectors are similarly defined. The source vector containing the production/destruction terms of the 
turbulent kinetic energy and specific dissipation transport equations can be written in the following form:

$$
H=\left[\begin{array}{c}
P_{k}-\rho \varepsilon \\
C_{\varepsilon 1-\frac{1}{k} P_{k}-C_{\varepsilon 2} f_{\varepsilon} \frac{\rho \varepsilon^{2}}{k}}
\end{array}\right]+\Lambda+\Lambda_{c}
$$

where the production and the Reynolds stresses are defined as follows. Here, a linear stress-strain approximation for the Reynolds stresses is employed.

$$
\begin{gathered}
P_{k}=\rho \tau_{i j}\left[\frac{\partial u}{\partial x_{i}}\right] \\
\rho \tau_{i j}=\mu_{t}\left[\left[\frac{\partial u_{i}}{\partial x_{j}}+\frac{\partial u_{j}}{\partial x_{i}}\right]-\frac{2}{3}\left[\frac{\partial u_{k}}{\partial x_{k}} \delta_{i j}\right]\right]-\frac{2}{3} \bar{\rho} k \delta_{i j}
\end{gathered}
$$

The turbulence modeling constants are shown in Table 1

\begin{tabular}{|l|c|c|c|c|c|}
\hline Models & $C_{\varepsilon 1}$ & $C_{\varepsilon 2}$ & $C_{\mu}$ & $\bar{\sigma}_{\kappa}$ & $\bar{\sigma}_{\varepsilon}$ \\
\hline \hline Chien & 1.35 & 1.80 & 0.09 & 1.0 & 1.3 \\
\hline
\end{tabular}

Table 1: Turbulence Model Parameters

A low-Reynolds number $k-\varepsilon$ model proposed by Chien $^{21}$ is used because of its favorable convergence behavior and numerical stability. ${ }^{18}$ However, this twoequation model number formulation has a disadvantage in that the low Reynolds number corrections are not Galleaninvariant; it is dependent on the grid coordinate system and the geometry. Therefore, a major disadvantage of this formulation is that for complex geometries the near wall characteristics may not be uniquely defined; for some cases, there may be wide range of possibilities. Here, the original model formulation has been extended into a three dimensional compressible formulation by closely following the two dimensional form previously reported. ${ }^{18}$ The low-Reynolds number correction terms for the Chien model are defined as follows:

$$
\begin{gathered}
\Lambda=\left[\begin{array}{c}
-2 \mu \frac{k}{2} \\
y_{n} \\
-2 \mu \frac{\varepsilon}{2} \exp \left(-0.5 y_{n}^{+}\right) \\
y_{n}
\end{array}\right] \\
f_{\mu}=1.0-\exp \left(0.0115 y_{n}^{+}\right)
\end{gathered}
$$

where $y_{n}$ is defined as nearest wall normal distance and ${ }^{+}$ is used to denote non-dimensionalization based only on wall characteristics. Here, the Van-Driest damping function is enforced with respect to the nearest wall.

\section{L.b Compressibility Effects}

In compressible flow situations, the mass weighted averaging procedure used to formulate the governing equations yields fewer unknown terms than the conventional Reynolds averaging procedure. ${ }^{14}$ Unfortunately, this procedure does not eliminate the need for additional modeling work needed for the mass fluctuation and dilatation terms. Modeling of the dilatational terms is essential in accurate predictions of high speed combustors because these terms directly contribute to the overall turbulent energy gain or loss caused by the volumetric fluctuations. Turbulence energy loss caused by additional compressible behavior is modeled using a modified form of the dilatation dissipation suggested by Wilcox. ${ }^{13}$ The mass averaged velocity ${ }^{12}$ is modeled according to the gradient diffusion hypothesis:

$$
\begin{gathered}
\Lambda_{c}=\left[\begin{array}{c}
-\alpha\left(M_{t}^{2}-0.06\right) \varepsilon H\left(M_{t}-0.25\right)+M A S \\
C_{\varepsilon 1 \frac{\varepsilon}{k} M A S}
\end{array}\right] \\
\text { MAS }=\left(\bar{u}^{\prime \prime} \frac{\partial p}{\partial x}+\bar{v}^{\prime \prime} \frac{\partial p}{\partial y}+\bar{w}^{\prime \prime} \frac{\partial p}{\partial z}\right) \quad \bar{u}^{\prime \prime}{ }_{i}=c \frac{\mu_{t} \partial \rho}{\rho^{2}} \frac{\partial x_{i}}{\partial x_{i}}
\end{gathered}
$$

where $H(x)=1.0$ for $x>0$ and $H(x)=0.0$ for $x<0$.

\section{Diffusion Model}

The models used to determine the mass-averaged coefficients governing the diffusion of momentum, energy, and mass can be described as follows. The individual species viscosity $(\mu)$ and conductivity $(\kappa)$ are computed using fourth order polynomial expressions developed by Gordon and McBride. ${ }^{23}$ These expressions have been shown to be accurate up to $6000^{\circ} \mathrm{K}$ and are adequate for the problems investigated $\left(<2500^{\circ} \mathrm{K}\right)$.

$$
\mu_{n}=\sum_{k=0}^{4} C_{\mu_{n}}(k) T^{k} \quad \kappa_{n}=\sum_{k=0}^{4} C_{\kappa_{n}}(k) T^{k}
$$

Once the individual species viscosities are found, the mixture viscosity and conductivity are computed using Wilke's mixing rule,

$$
\mu=\sum_{n=1}^{N_{s}} \frac{\mu_{n}}{\frac{1}{X_{n}} \sum_{j=1}^{N_{s}} X_{j} \phi_{n j}} \quad \kappa=\sum_{n=1}^{N_{s}} \frac{\kappa_{n}}{\frac{1}{X_{n}} \sum_{j=1}^{N_{s}} X_{j} \phi_{n j}}
$$


Here, the inter-collisional parameter $(\phi)$ between species $\mathrm{n}_{1}$ and $n_{2}$ is defined as:

$$
\phi_{n_{1} n_{2}}=\left(\sqrt[2]{8\left(1+\frac{M W_{n_{1}}}{M W_{n_{2}}}\right)}\right)^{-1}\left(1+\sqrt[4]{\frac{M W_{n_{2}}}{M W_{n_{1}}}} \sqrt{\frac{\mu_{n_{1}}}{\mu_{n_{2}}}}\right)^{2}
$$

The inter-species diffusion is modeled using the Chapman-Enskog formulation for dilute gases:

$$
D_{n_{1}, n_{2}}=0.0018583 \sqrt{\frac{1}{W M_{n_{1}}}+\frac{1}{W M_{n_{2}}}}\left(\frac{1}{\sigma_{n_{1} n_{2}}^{2}}\right)\left(\frac{T_{D}^{1.5}}{P \Omega_{D}}\right)
$$

where $\sigma_{i j}=\frac{1}{2}\left(\sigma_{i}+\sigma_{j}\right)$ and the effective collision integral factor, $\Omega_{D}$, and the effective temperature, $T_{D}$, are approximated by:

$$
\Omega=\frac{1}{T_{D}^{0.145}}+\frac{1}{\left(T_{D}+0.5\right)^{2}} \quad T_{D}=\frac{T}{\sqrt{T_{\varepsilon} T_{\varepsilon}}}
$$

The physical properties of the gas components and the reference enthalpy needed are summarized in Table 2.

The overall diffusion coefficients were computed by lumping all of the species together into a mixture and then determining the binary diffusion between the $i^{\text {th }}$ species and the mixture. The diffusion coefficient, $D_{i j}$, is defined in Equation 14. Once the binary diffusion coefficients for all of the species combinations and the mixture are known, the diffusion velocity of each species is found using Fick's law. Therefore, the inter-species diffusion velocity components, $\left(\overline{\mathrm{u}}_{\mathrm{i}}\right)_{\mathrm{j}}$, are defined as:

$$
Y_{i}\left(\hat{u}_{i}\right)_{j}=-D_{i m} \frac{\partial Y_{i}}{\partial x_{j}} \quad D_{i m}=\frac{1-X_{i}}{\sum_{m \neq i}^{N_{s}} \frac{X_{m}}{D_{i m}}}
$$

The turbulent diffusion of mass was modeled based on assumptions that the eddy diffusivity is directly proportional to the turbulent mass diffusivity by a constant, the turbulent Schmidt number $(S c t)$, and that the gradient-diffusion process also applies to the turbulent diffusion process, i.e. $D_{i j}=\left(D_{i j}\right)_{l a m}+\mu_{\mathrm{t}} / \mathrm{\rho} / S c t$. For the k- $\varepsilon$ model predictions, $S c t$ was assumed to 0.9 ; for the Baldwin-Lomax model prediction, Sct was assumed to be 0.5 .

\section{Thermodynamic model}

The mass-averaged specific heat constant at constant pressure $\left(C \mathrm{p}_{\mathrm{i}}\right)$ of the individual species is assumed to be a fourth order polynomial function of temperature. Curve fitted constants have been adopted from Gordon and
McBride. ${ }^{23}$ Once the individual species thermodynamic properties, such as specific heat and gas constant, have been found, the mixture properties can be found by weighting them over all of the species. Typically, the specific heat and the corresponding mixture relationship are defined as:

$$
C p_{i}=\sum_{k=0}^{4} C p_{i}(k) T^{k} \quad \overline{C p}=\sum_{n=1}^{N_{s}} C p_{i} Y_{i}
$$

The internal energy of the gas mixture is determined by using mixture properties such as pressure, density and enthalpy, and is defined as:

$$
e=\sum_{i=1}^{N_{s}} Y_{i} h_{i}-\frac{p}{\rho}+\frac{1}{2}\left(u^{2}+v^{2}+w^{2}\right)
$$

$$
h_{i}=h_{0}+\int_{T r}^{T} C p_{i} d T
$$

Here, $h_{0 i}$ is the reference enthalpy at standard temperature $\left(T_{r}\right)$ and is shown in Table 2. Since the specific heat of the species is formulated as a function of temperature only, the enthalpy relationship can be easily integrated to yield a polynomial relationship between enthalpy and temperature for the gas mixture. Newton's iteration is used to find the temperature from the predicted internal energy of the gas mixture. Here, the pressure of the gas mixture is determined from Dalton's law of partial pressure:

$$
p=\rho \bar{R} T \sum_{i=1}^{N_{s}} \frac{Y_{i}}{M W_{i}}
$$

\section{Finite Rate Chemistry Model}

Chemical balance of the $\mathrm{N}_{s}$ species and $\mathrm{N}_{\mathrm{r}}$ reaction finite rate reaction model is determined from stoichiometric equation. $^{24}$.

$$
\sum_{n=1}^{N_{r}} v^{\prime \prime}{ }_{i k} C_{i} \sum_{n=1}^{N_{r}} v^{\prime}{ }_{i k} C_{i}
$$

where $v^{\prime}{ }_{i k}$ and $v^{\prime \prime}{ }_{i k}$ are stoichiometric coefficients and $C_{i}$ is chemical symbol of $i^{\text {th }}$ species.

The Law of Mass Action states that the rate of change of concentration of the $i^{\text {th }}$ species is defined by the movement of each species summed over all of the contributing reactions. Therefore, if $n_{i}$ is assumed to be the 
molar concentration $\left(=\rho Y, M W_{i}\right)$. Then, the rate of change in species concentration can be expressed as follows:

$$
\omega_{i}=M W_{i} \sum_{K=1}^{N_{r}}\left(\pi_{i k}\left(K_{f}(k) \prod_{j=1}^{N_{s}} n_{j}^{v^{\prime}{ }_{j k}}-K_{b}(k) \prod_{j=1}^{N_{s}} n_{j}^{v^{\prime \prime} i k}\right)\right)
$$

where $\pi_{i k}=v^{n}{ }_{i k}-v^{\prime}{ }_{i k}$. The forward and backward reaction rates $\left(K_{f}, K_{b}\right)$ are computed from Arrhenius' relationship with phenomenologically developed chemical rate constants. The forward reaction rate constants of the $k^{\text {th }}$ reactant are defined as:

$$
K_{f}(k)=A_{f}(k) T^{\alpha} f^{(k)} \exp \left(\frac{E_{f}(k)}{R_{u} T}\right)
$$

The reverse reaction rate $\left(K_{\mathrm{r}}\right)$ is similarly defined. The laminar reaction rate constants for a $\mathrm{H}_{2}$-air model are summarized in Table 4.

\section{Numerical Techniques}

Once the thermal, chemical and turbulent properties have been computed, the LU-SSOR technique originally proposed by Yoon and Jameson ${ }^{16}$ is used to find the steady-state solution. In order to handle complex geometry, the governing equations are solved in a body fitted coordinate system $(\xi, \eta, \zeta)$.

$$
\frac{\partial \grave{Q}}{\partial \tau}+\frac{\partial}{\partial \xi}\left(\hat{E}-\hat{E}_{v}\right)+\frac{\partial}{\partial \eta}\left(\hat{F}-\hat{F}_{v}\right)+\frac{\partial}{\partial \zeta}\left(\hat{G}-\hat{G}_{v}\right)=H
$$

where the typical conservative vectors are defined as:

$$
\begin{gathered}
\hat{Q}=h Q \\
\hat{E}=h\left(\xi_{x} E+\eta_{x} F+\zeta_{z} G\right) \\
\hat{E}_{v}=h\left(\xi_{x} E_{v}+\eta_{x} F_{v}+\zeta_{x} G_{v}\right) \\
\hat{H}=h H
\end{gathered}
$$

The implicit finite volume formulation of the finite differenced governing equations is linearized to the following delta expression:

$$
\begin{gathered}
L S^{-1} U \Delta \hat{Q}=\Delta t R H S \\
L=\left(I+\Delta t\left(D_{\xi}^{-} \hat{A}^{+}+D_{\eta}^{-} \hat{B}^{+}+D_{\zeta}^{-} \hat{C}^{+}-\hat{A}^{-}-\hat{B}^{-}-\hat{C}^{-}-\hat{T}\right)\right) \\
U=\left(I+\Delta t\left(D_{\xi}^{-} \hat{A}^{-}+D_{\eta}^{-} \hat{B}^{-}+D_{\zeta}^{-} \hat{C}^{-}-\hat{A}^{+}-\hat{B}^{+}-\hat{C}^{+}\right)\right) \\
S=\left(I+\Delta t\left(\hat{A}^{+}+\hat{B}^{+}+C^{+}-\hat{A}^{-}-\hat{B}^{-}-C^{-}\right)\right)
\end{gathered}
$$

where the explicit right handside(RHS) is

$$
R H S=D_{\xi}\left(\hat{F}-\hat{F}_{v}\right)+D_{\eta}\left(\hat{G}-\hat{G}_{v}\right)+D_{\eta}\left(\hat{G}-\hat{G}_{v}\right)+\hat{H}
$$

The flux Jacobians $A^{+}, A^{-}, B^{+}, B^{-}, C^{+}$and $C^{-}$are constructed such that the eigenvalues of $A^{+}, B^{+}$and $C^{+}$are positive and the eigenvalues of $A^{-}, B^{-}$and $C^{-}$are negative.
There are several methods of splitting the Jacobian matrices to achieve the needed sign. A splitting procedure suggested by Yoon and Jameson, ${ }^{16}$ based on global spectral radii, has been adopted. The final delta form of the governing equation is developed by splitting the Jacobians into positive and negative parts and upwind differencing the governing equation. This procedure enables us to split the implicit side of the numerics into a Upper and Lower form shown in Equation 23 for $\Delta Q$. If no mass transfer $\left(\omega_{k}=0\right)$ is present, as is the case in non-reacting or chemically equilibrium situations, only two scalar inversions are needed to solve Equation 23. For finite rate calculations, the first operator $(L)$ in Equation 23 requires point block diagonal inversion because of the implicit coupling of the chemical source terms. This implicit procedure is essentially equivalent to re-scaling the characteristic time scale of the governing equations and is essential for numerical stability. Furthermore, this implicit procedure is much more efficient than explicit procedures in which the numerical stability is further limited by the chemical time scales, which can be orders of magnitude smaller than the convective time scales. The three dimensional LU implicit procedure can be written in the following form:

$$
\begin{gathered}
\Delta \hat{Q}_{i j k}^{I}=\Delta t\left(I+\Delta t\left(\frac{\gamma_{A}}{\Delta \xi}+\frac{\gamma_{B}}{\Delta \eta}+\frac{\gamma_{C}}{\Delta \zeta}\right)\right) R H S \\
+\frac{\Delta t}{\Delta \xi} \hat{A}_{i-1, j, k}^{+} \Delta \hat{Q}_{i-1, j, k}^{I} \\
\Delta \hat{Q}_{i j k}^{I I}=\Delta \hat{Q}_{i j k}^{I}+\frac{\Delta t}{\Delta \eta} \hat{B}_{i, j-1, k}^{+} \Delta \hat{Q}_{i, j-1, k}^{I I} \\
\left(I+\Delta t\left(\frac{\gamma_{A}}{\Delta \xi}+\frac{\gamma_{B}}{\Delta \eta}+\frac{\gamma_{C}}{\Delta \zeta}\right)-\Delta t T_{i j k}\right) \Delta \hat{Q}_{i j k}^{I I I}=\Delta \hat{Q}_{i j}^{I I} \\
-\frac{\Delta t}{\Delta \eta} \hat{C}_{i, j, k-1}^{+} \Delta \hat{Q}_{i, k-1}^{I I I}
\end{gathered}
$$

$$
\begin{gathered}
\Delta \hat{Q}_{i j k}^{I V}=\Delta \hat{Q}_{i j k}^{I I I}-\frac{\Delta t}{\Delta \xi} \hat{A}_{i+1, j, k} \hat{Q}_{i+1, j, k}^{I V} \\
\Delta \hat{Q}_{i j k}^{V}=\Delta \hat{Q}_{i j k}^{I V}-\frac{\Delta t}{\Delta \eta} \hat{B}_{i, j+1, k} \Delta \hat{Q}_{i, j+1, k}^{V}
\end{gathered}
$$$$
\left(I+\Delta t\left(\frac{\gamma_{A}}{\Delta \xi}+\frac{\gamma_{B}}{\Delta \eta}+\frac{\gamma_{C}}{\Delta \zeta}\right)\right) \Delta \hat{Q}_{i j k}=\Delta \hat{Q}_{i j k}^{V}
$$$$
-\frac{\Delta t}{\Delta \xi} \hat{C}_{i, j, k+1}^{-} \Delta \hat{Q}_{i, j, k+1}
$$ 
where the split flux Jacobian is defined as,

$$
\hat{A}^{ \pm}=\frac{1}{2}\left(\hat{A} \pm \gamma_{A} I\right)
$$

$B^{+}, B, C^{+}$, and $C$ are similarly defined.

The turbulent kinetic energy and specific dissipation rate transport equations are only weakly coupled ${ }^{18,19}$ to the mean equations through eddy viscosity. Therefore, the turbulence transport equations are solved uncoupled from the mean equations. This decoupling maintains the rank of the Jacobian matrices for the mean flow solver at thirteen and requires only a two by two matrix solver for the turbulence equations. On the right hand(physics) side of Equation 23, a central differencing technique with a numerical filter introduced by Jameson ${ }^{20}$ is used. In this uncoupled procedure, the time marching of the turbulence transport equations lags the mean equations marching by one iteration. While the decoupling greatly simplifies the algorithm, additional iterations may be required to resolve any sudden changes in the numerical solutions because of the numerical accuracy lost in the decoupling procedure. Furthermore, it is possible that the decoupling can cause numerical instabilities during early stages of the computation, when rapid changes in the solution are expected. Therefore, additional limiters for turbulent kinetic energy and dissipation were adopted to insure numerical stability.

The source term $(H)$ contains the effect of turbulent energy transfer between the dissipative scales and energy containing scales as well as the low Reynolds effects. Therefore, proper numerical treatment of these terms is essential in turbulent flow solver development. In high shear situations, this term tends to get extremely stiff and therefore in most cases the implicit representation of this term is essential in maintaining numerical stability. This difficulty is further extenuated when the turbulence model is expected to handle a rapid exchange in turbulent energy between the dissipative scales and the turbulent energy scales due to externally generated gradients such as shockwaves and their interaction with the turbulent boundary layer. Similar observations have been made by other investigators. ${ }^{18,19}$ However, the exact formulation of the source flux Jacobian term varies from study to study. Initially, we have used the following $2 \times 2$ matrix for the source Jacobian on the left hand side of the Equation 24:

$$
T_{i j}=\left[\begin{array}{cc}
\left(\frac{\bar{P}_{k}}{\rho k}-\frac{\varepsilon}{k}\right) & 0 \\
0 & C_{\varepsilon 1 \frac{\varepsilon}{k}}\left(\frac{\bar{P}_{k}}{\rho \varepsilon}-2 f_{\varepsilon} \frac{C_{\varepsilon 2}}{C_{\varepsilon 1}}\right)
\end{array}\right]
$$

Huang and Coakley ${ }^{25}$ showed that in order to maintain numerical stability the source Jacobian should be formulated so that the overall numerical scheme maintains a positive left hand side. Therefore, only the negative part of the production term $\left(\bar{P}_{K}\right)$ is represented in the source Jacobian.

\section{Boundary and Initial Conditions}

The combustor walls were assumed to be adiabatic and non-catalytic. At the wall surfaces, zero boundary conditions for turbulent kinetic energy and specific dissipation were used. Zero gradient conditions were assumed at the freestream boundaries. The inlet velocity profile was developed from the initial value of the skin friction coefficient, boundary-layer thickness and the law of the wall assumptions. The compressible law of the wall transformation proposed by Van Driest was then used to account for the effects of compressibility. Furthermore, the velocity and the temperature profiles was assumed to be similar non-dimensionally. Therefore, once the velocity profile is developed the thermal profile can also be completely developed. Finally, the turbulent kinetic energy and dissipation rate profiles were developed from the following empirical relationships:

$$
k=\frac{3}{2}\left(T_{u} U\right)^{2} \quad \varepsilon=C_{\mu}^{3 / 4} \frac{k^{3 / 2}}{l}
$$

where the characteristic length scale is assumed to be

$$
l=\min (0.4 y, 0.085 \delta)
$$

\section{Test Cases}

Several non-reacting and reacting injector/combustor flowfields were studied to evaluate the numerical technique and the $\mathrm{k}-\varepsilon$ turbulence model solver developed. First, a problem of chemical reaction in premixed gas was considered to assess the influence of turbulence models in the predictions of shock-induced combustion. Secondly, predictions of non-reacting combustor flowfields were obtained for a transverse injector/backstep combustor and the solutions were compared with experimental measurements ${ }^{29}$ to study effects of the turbulence in typical combustor flowfield predictions. Third, reacting and non-reacting solutions to ramp injector/combustor flowfields ${ }^{28,29}$ were obtained to illustrate the influence of geometry and chemical reactions on the turbulence model predictions.

Laminar and turbulent solutions to premixed $\mathrm{H}_{2}$-air flow over a ten degree ramp were obtained to illustrate the effects of turbulence on chemical reactions. The inlet Mach number is 4.5 , and the static pressure and temperature are assumed to be 1 ATM and $900 \mathrm{~K}$, respectively. A stoichiometric hydrogen and air mixture is the freestream gas. This configuration is similar to the problem reported by Yungster. ${ }^{30}$ Figure 1 shows normalized pressure and temperature distributions at a small distance from the wall for both reacting and nonreacting flows. The open symbol is used to denote pressure and temperature profiles obtained from the non-reacting flow solution and the solid line is used for profiles obtained from the reacting flow. This figure clearly shows the rise in wall temperature caused by the chemical reaction; this rise is preceded by slight ignition delay behind the shock wave. 
Page intentionally left blank 


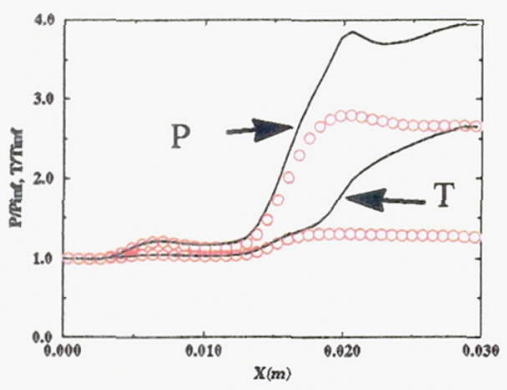

Figure 1. Near-Wall Temperature and Pressure Distribution

A similar comparison of turbulent solutions obtained using the Baldwin-Lomax $(\mathrm{BL})$ turbulence model $^{26}$ and the present $\mathrm{k}-\varepsilon$ model on the same grid system is shown in Figure 2. The solid line in Figure 2 is the $\mathrm{k}-\varepsilon$ model prediction, and the open symbols are used to denote the solution obtained from the zero-equation model. Here, the $\mathrm{k}-\varepsilon$ model solution does not include compressibility corrections (i.e. $\alpha=0, \overrightarrow{\mathrm{u}^{3}}=0$ ). As with the laminar solutions, the majority of the chemical reactions take place in the near wall region behind the shockwave, where favorable thermodynamic conditions exist. The difference between BL model and $\mathrm{k}-\varepsilon$ model solutions is small because of the low-Reynolds number of the problem and the low turbulence intensity $\left(\mathrm{T}_{u}=0.5 \%\right)$ used in the $\mathrm{k}-\varepsilon$ model prediction. However, it is worthwhile to note that there are differences in the boundary-layer characteristics and the shock-wave angle predicted by the two models, shown in Figure 2, especially around the corner region. This indicates that the boundary-layer characteristic predicted is a strong function of the turbulence model employed. Similar behavior was even observed in absence of chemical reactions. ${ }^{18}$ Furthermore, the rise in temperature through the shock-wave and the subsequent rise in surface heating causing the ignition are predicted at different ramp locations by the two models. Further evidence of chemical reaction is shown in Figure 3, where fuel $\left(\mathrm{H}_{2}\right)$, oxidant $\left(\mathrm{O}_{2}\right)$, hydroxyl $(\mathrm{OH})$ and water $\left(\mathrm{H}_{2} \mathrm{O}\right)$ mass fraction profiles are plotted. The premixed air-hydrogen burns behind the shock-wave, causing the temperature to rise and water to be produced.

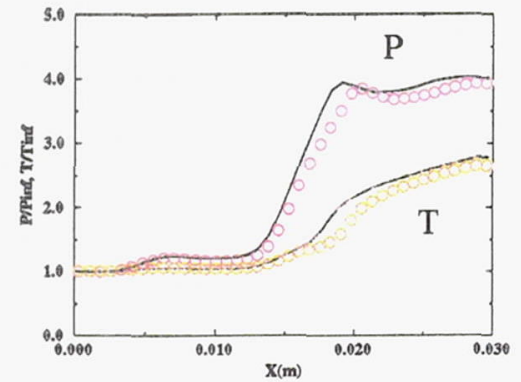

Figure 2. Near-Wall Temperature and Pressure Distribution of BL and k- $\varepsilon$ Model Predictions

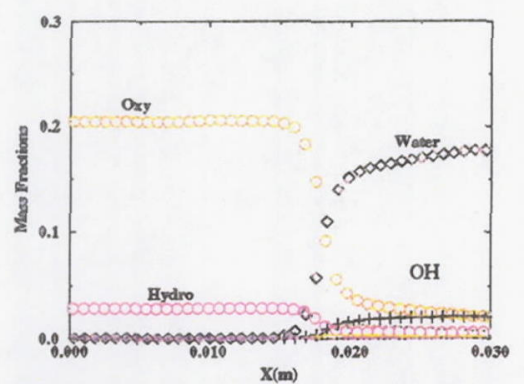

Figure 3. Chemical Species Distributions

In order to further test the three dimensional solver with the $\mathrm{k}-\varepsilon$ model of turbulence, a transverse injector/ constant area combustor flowfield was studied and the numerical solution is compared with the experimental data obtained by McDaniel. ${ }^{29}$ In this combustor design, a rearward facing step is used to create a recirculation region that acts as a flame-holder. This rearward facing step is followed by two injection ports located at the bottom wall of the test section where the fuel(seeded-air) is injected transversely. In order to reduce computational resource required, the flowfield was assumed to be symmetric about a XY-plane located along the centerline of the combustors. A typical geometry of the constant area combustor model with transverse injectors is shown in Figure 4. Two block computational grid systems similar to those used by Lee $e^{10}$ were also used here. Here, a block of grid was used to model the main combustor and a block of grid was used to model the flowfield inside of the wind tunnel prior to the backstep. The grid cells along the no-slip walls around the injectors and the combustor were stretched using a hyperbolic tangent function to maintain a near-wall nondimensional height $\left(\mathrm{y}^{+}\right)$of approximately 1.0 at the inlet location. For this problem a half percent turbulence level was assumed in the $\mathrm{k}-\varepsilon$ model prediction. The incoming boundary-layer characteristics were developed from a loglaw based formulation. ${ }^{18}$ The combustor walls were assumed to adiabatic and non-catalytic. The two-air mode $1^{10}$ was used to match experimental conditions. In order to further simplify the calculation, only the noslip surface along the bottom surface of the combustor has been resolved in the computation; all other wall surfaces are assumed to be slip walls. A zero gradient boundary condition has been assumed for the injector exit.

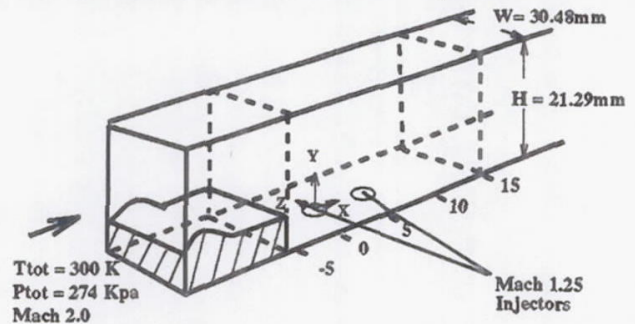

Figure 4. Typical Grid Geometry of Transverse Injector Typical two-equation model predictions of the centerplane pressure and temperature are shown in Figures 5 and 6. These two figures clearly show that the essential flow features of the dual transverse injection system, including the backstep created circulation region, which entrains the injected fuel, and the formation of a dual bow shock-wave 
Page intentionally left blank 
around the injected gas columns. These pressure and temperature contours are in close agreement with the experimental data and the algebraic model predictions shown in Lee. ${ }^{10}$
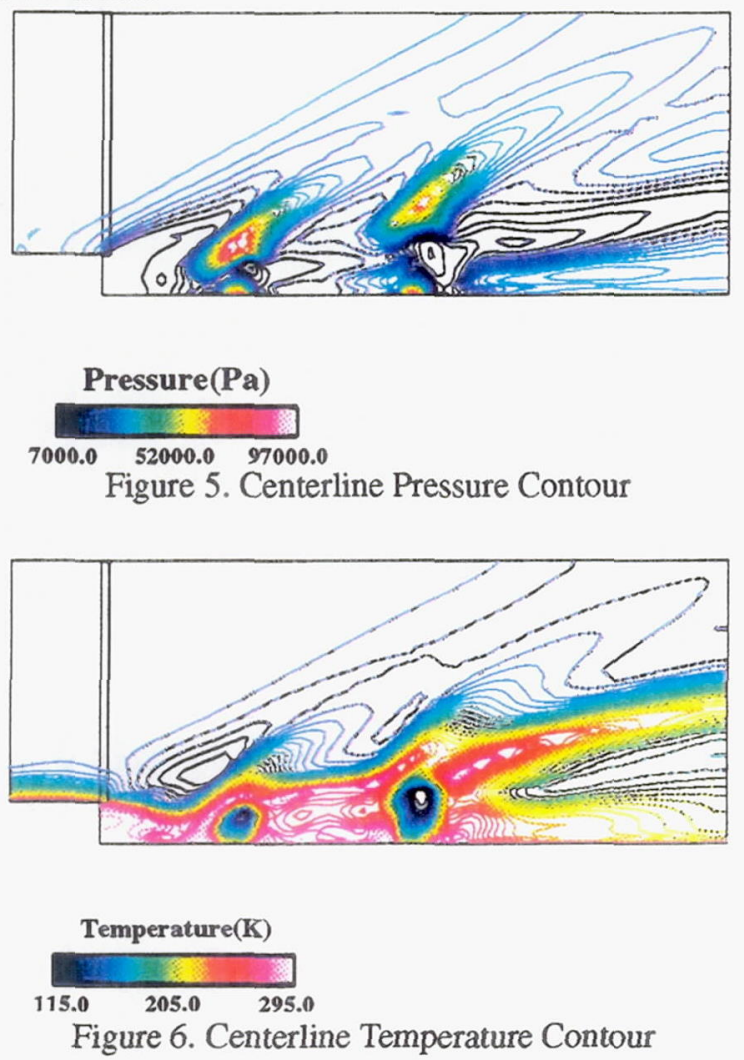

The eddy viscosity contours predicted are shown in Figure 7. This figure shows the weakness of using a lowReynolds model formulation with Van-Driest damping function. The separation, reattachment, and the injector boundary conditions cause the wall shear stress and therefore the damping function of Equation 7 to go to zero; as a result the eddy viscosity also goes to zero. This behavior causes discontinuity in the predicted eddy viscosity distribution, shown as spikes in Figure 7. Further work is needed to eliminate this difficulty in the model formulation. A typical centerline turbulent kinetic energy distribution predicted is shown in Figure 8 . The essential features of the predicted turbulent kinetic energy are consistent with the flowfield physics; for example, high turbulence intensities occur in the high shear regions caused by shock waves and the shear flow mixing generated by the backstep. Typical centerline velocity, pressure, and temperature profiles at three streamwise stations along the combustor centerplane are compared with the experimental data in Figures 9 through 11. In these figures the open symbols denote experimental data obtained by McDaniel, ${ }^{29}$ and the lines represent the predictions. In particular, the solid lines denote the $\mathrm{k}-\varepsilon$ model prediction and dashed lines denote the BaldwinLomax model prediction. These comparisons clearly show that reasonable predictions can be made with the new $\mathrm{k}-\varepsilon$ model approach. The BL model and $\mathrm{k}-\varepsilon$ model predictions are in rather close agreement with each other because of the low turbulence intensity used in the $\mathrm{k}-\varepsilon$ model prediction. The only appreciably distinguishable feature is seem at the second station, where the re-circulation predicted by the $\mathrm{k}-\varepsilon$ model is stronger than either the measured value or the zero-equation model prediction. This difficulty may be the result of the singular eddy viscosity value predicted upstream of this location at the injector ports. At first glance, these results do not indicate any distinctive advantages of using a transport model over a zero-equation model. However, it is important to note that the $\mathbf{k}-\varepsilon$ model approach allows for further generality and physical flexibility not found in the algebraic model formulation and not tested here. These model flexibilities include the ability to model the influence of freestream turbulence intensity and the fuel jet turbulence characteristics on the combustor flow field predictions.
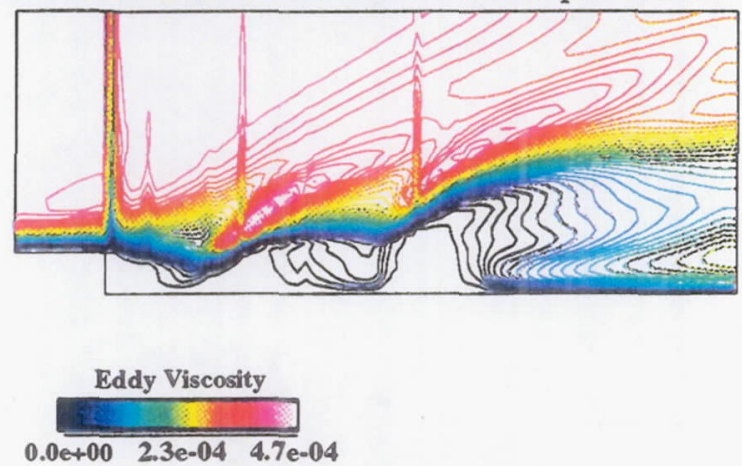

Figure 7. Centerline Eddy Viscosity Contour
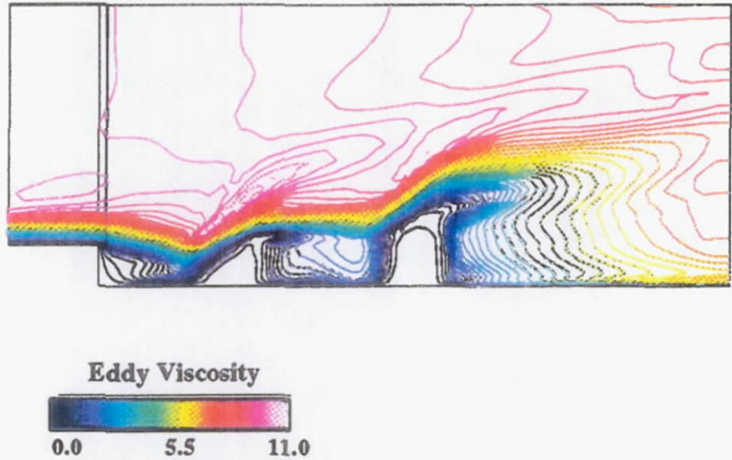

Figure 8. Centerline Turbulent Kinetic Energy Contour

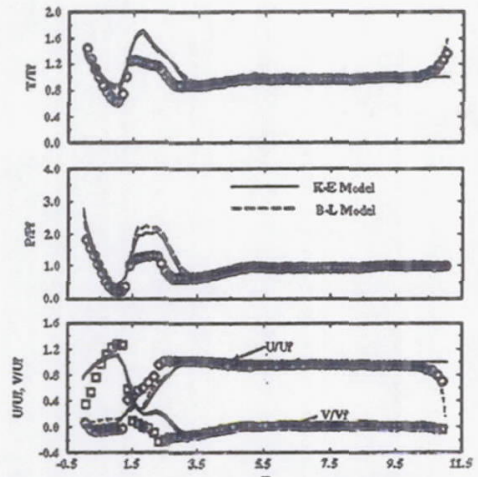

Figure 9. Typical Temperature, Pressure, and Velocity Profiles $(\mathrm{X} / \mathrm{D}=0.0)$ 
Page intentionally left blank 

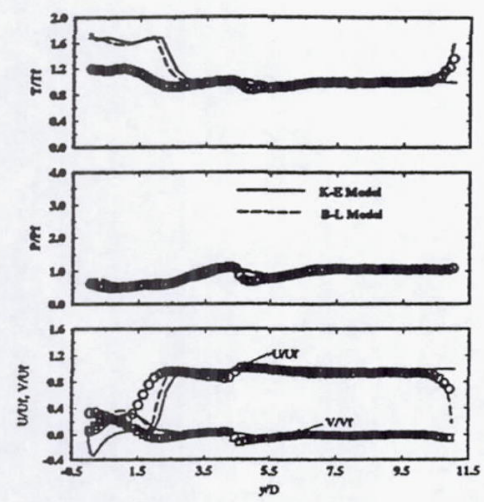

Figure 10. Typical Temperature, Pressure, and Velocity Profiles $(\mathrm{X} / \mathrm{D}=3.1)$

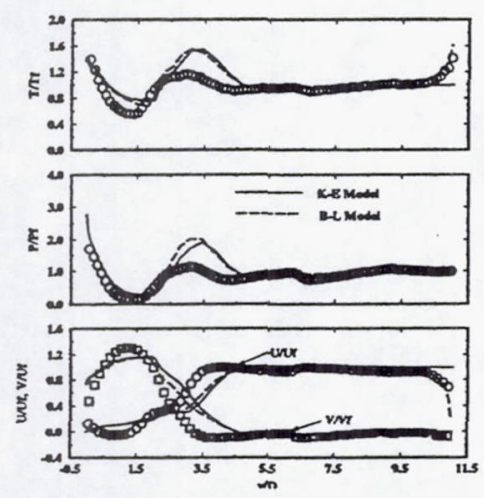

Figure 11. Typical Temperature, Pressure, and Velocity Profiles (X/D $=6.6$ )

The new turbulence model-solver combination was used to solve the chemically reacting and non-reacting combustor/injector flowfields. These complex threedimensional swept and straight ramp hypermixing injector designs are important in developing high efficiency combustors. Typical geometry of the swept ramp injector is shown in Figure 12. The ramp angle is 9.5 degrees and the sweep angle is at 9.0 degrees. The straight ramp geometry was generated using the same ramp angle and zero sweep angle. Both injector geometries were numerically resolved using three block grid system similar to that used in reference 10. In order to obtain combustion, the freestream and the injector static conditions were raised to match the test conditions of NASA Langley's combustor test facility. Here, the inflow Mach number was assumed to be 2.0. The freestream gas is assumed to be vitiated air made up of $25.6 \%$ oxygen, $56.2 \%$ nitrogen, and $18.2 \%$ water. The freestream pressure and temperature are assumed to be $1.0 \times 10^{5} \mathrm{~Pa}$ and $1024^{\circ} \mathrm{K}$, respectively. The physical conditions, geometrical features, and computational performance of the computation are summarized in Table 4. Fuel-air equivalence ratios of $90 \%$ and $60 \%$ were investigated. Typical convergence characteristics of the mean variables and the turbulence scalar quantities are shown in Figure 13. In this work, two orders of reduction in the total residual for all variables was assumed to be adequate for convergence.

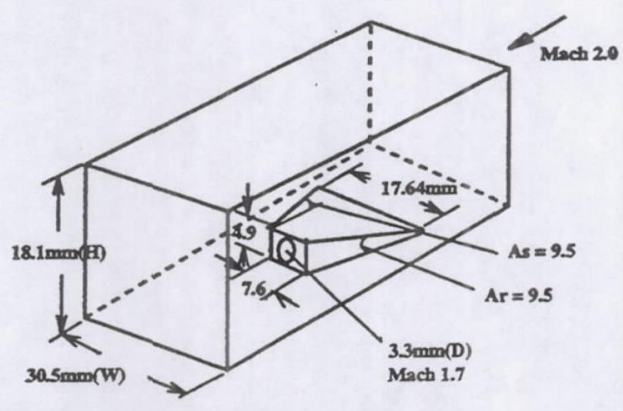

Figure 12. Swept Ramp Injector Geometry

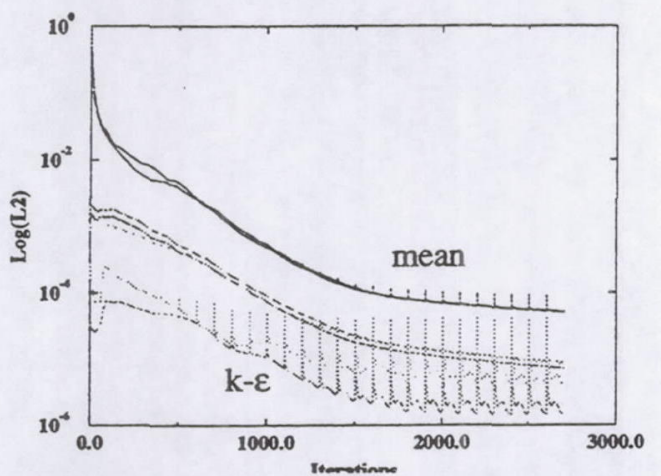

Figure 13. Typical Residual Characteristics

The chemically reacting solutions are shown along with non-reacting(mixing) solutions to illustrate the influence of exothermic reactions on the turbulent flow field predictions. Typical water mass fractions predicted at several streamwise locations for the two fuelair equivalence ratio are shown in Figure 14. This figure also shows that the strength and shape of the streamwise vorticity developed by the swept injector is not significantly influenced by the chemical reactions. The low combustion efficiency achieved for these flow conditions can be a contributing factor for this behavior. Therefore, flows with higher turbulence intensities with additional chemical reactions should be further investigated for additional insight. In this configuration, the majority of the chemical reactions occur in the core region of the streamwise rollup(vorticity), where low streamwise velocity due to ramp blockage is found. This is also the region where the majority of the water is produced. Figure 15 shows the typical static temperature distribution and, as expected, high temperature regions are developed by the combustion process which produced water. Figure 16 shows the typical wall temperature distribution; an extremely hot spot on the combustor wall is evident. The appearance of the hot spot on the wall temperature distribution is consistent with the experimental observations of Northam, ${ }^{28}$ where extremely high combustor wall temperature some distance from the injector exit was observed. In some cases, the high temperature encountered led to combustor wall failures. Figure 17 shows the turbulent kinetic energy distribution predicted. As expected, the higher turbulence intensities are found in the reacting flow. Furthermore, predicted turbulent kinetic energy profiles show physically 
Page intentionally left blank 
consistent trends in the turbulence intensities predicted. For example the high mean shear generated by the streamwise vorticity and shock-waves lead to higher turbulence intensities predicted. However, in the absence of experimental measurements definitive conclusions cannot be drawn from this trend. Furthermore, a number of physical modelling issues have not yet been explicitly addressed and the models used in this work may not adequately resolve the injector/combustor flowfield.

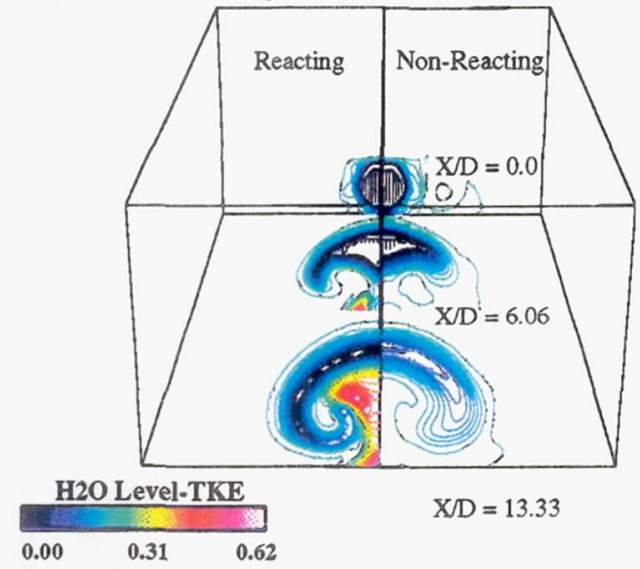

Figure 14. Influence of Chemical Reaction on the Water Predictions

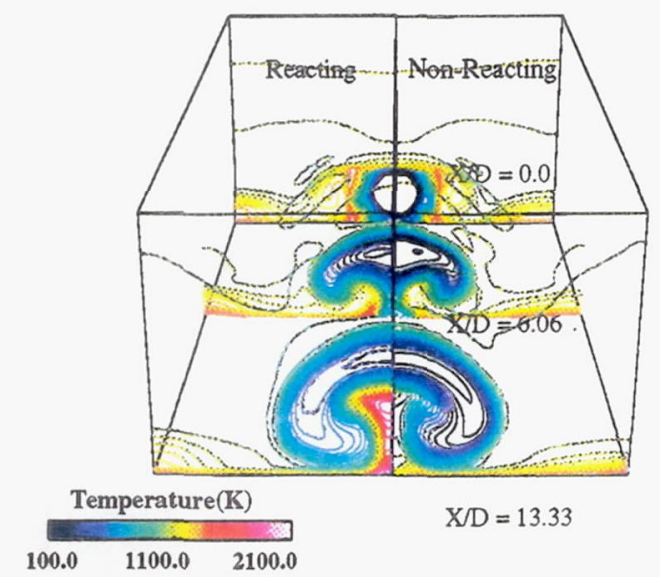

Figure 15. Influence of Chemical Reaction on the Temperature Predictions

An additional reacting combustor flowfield was computed to determine the influence of the fuel-air equivalence ratio. The overall equivalence ratio of the two injector experimental configuration in reference 28 is $120 \%$. In order to match the static condition of that experiment, an equivalent case of $60 \%$ fuel-air equivalence ratio was used to test single injector model. Here, only a short constant area section of the combustor duct was computed to minimize the thermal choking effects. The injector to combustor cross-sectional area ratio of the present combustor is different from the work of Northam. ${ }^{28}$ Therefore, only the exit Mach number and static pressures were matched; the static temperature of the fuel was raised to $629^{\circ} \mathrm{K}$ to achieved the desired fuel-air equivalence of $60 \%$. The flowfield predicted at this equivalence ratio is similar to earlier solutions.

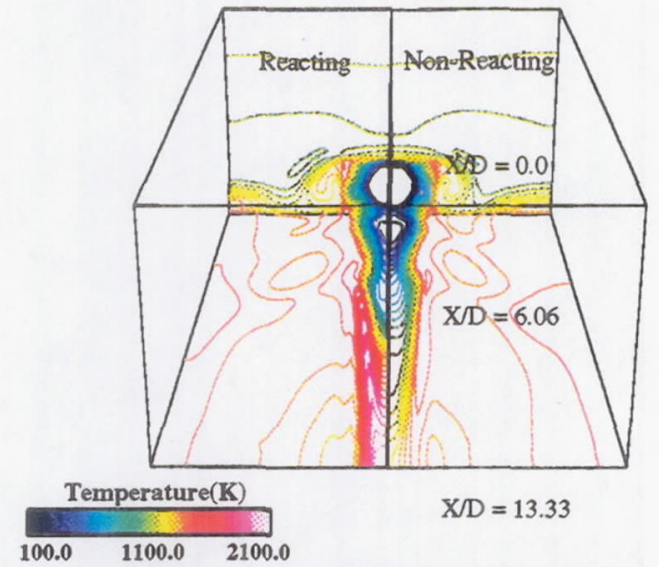

Figure 16. Influence of Combustor Wall Temperature Predictions

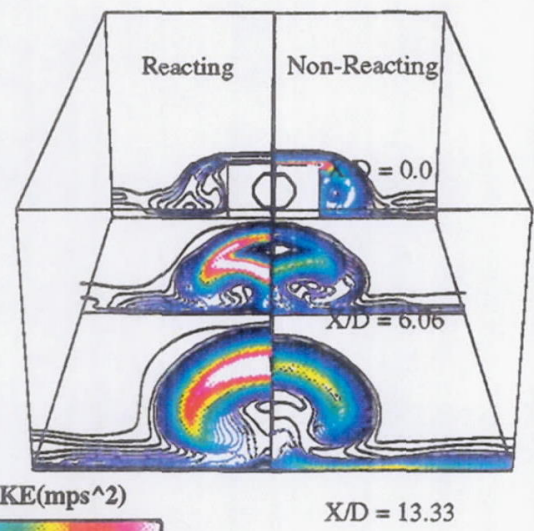

$\begin{array}{lll}0.0 e+00 & 5.0 e+04 & 1.0 e+05\end{array}$

Figure 17. Influence of Chemical Reaction on the

Turbulent Kinetic Energy Predictions

However, the thermal characteristics predicted have been dramatically altered. The evidence of extensive exothermic activity is shown in Figures 18 and 19. Figure 18 shows the water mass fraction levels predicted at various streamwise locations of the combustor for the two fuel-air equivalence levels studied. The hotter fuel in the $60 \%$ fuel-air equivalence ratio case causes extensive chemical reactions to take place in the combustor. These chemical reactions cause the temperature to rise and a large amount of water to be produced around the tail end and center core region of the streamwise vorticity created by the swept injector, where favorable thermodynamics conditions are present. All three fuel-air equivalence cases studied show similar flowfield features, including the formation of the butterfly shape that vortical rollup causes, with dramatically different combustion efficiencies. This figure further reinforces the idea that the shape of the streamwise vorticity is only weakly linked to the exothermic chemistry and strongly linked to the shape of the ramp injector. Figure 20 shows the influence of chemical reaction on the predicted turbulent kinetic energy. The overall flow feature shown in this figure is very similar to Figure 17 . However, in this case the 
Page intentionally left blank 
increase in exothermic chemical reaction leads to an increase in the peak turbulence intensity.

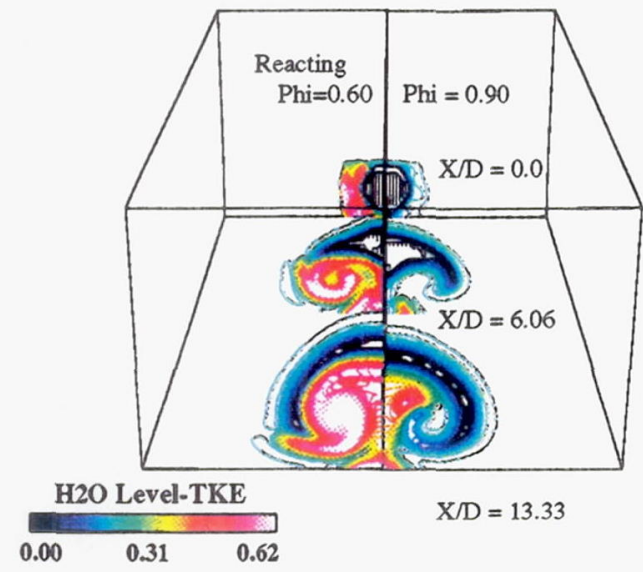

Figure 18. Effects of Fuel-Air Equivalence Ratio on the Water Mass Fraction Prediction

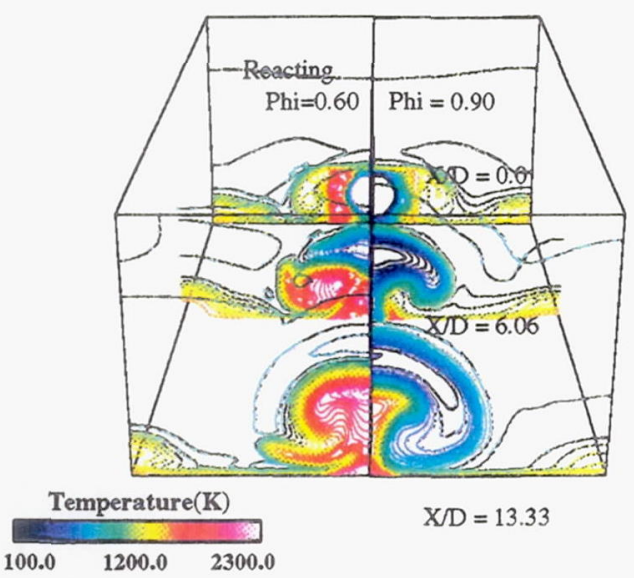

Figure 19. Effects of Fuel-Air Equivalence Ratio on the Temperature Prediction

The injector/combustor problems can also be characterized using non-dimensional efficiency parameters. Typical mixing and combustion efficiency predictions are shown in Figure 21. Here the mixing and combustion efficiency definitions proposed by Riggins ${ }^{30}$ have been adopted. Mixing efficiency is defined as the ratio of mass flux of least available reactant which would react if complete reaction occurred with no further mixing to total mass flux of the least available reactant. The combustion efficiency is defined as the ratio of the reacted mass flux of least available reactant to total mass of least available reactant. In Figure 21, open symbols are used to denote the combustion efficiency and the filled symbols are used to denote the mixing efficiency. In general Figure 21 shows that only a small amount of combustion occurs near the injector exit plane( $\mathrm{X} \sim \mathrm{D}$ region), where the supersonic fuel jet exhibits the under-expanded jet and limited mixing behavior. Furthermore, the increase in the combustion efficiency lags behind the increase in mixing efficiency which indicates that the fuel-air must be well mixed before combustion is possible. Figure 21 also clearly shows the influence that the exothermic chemical reaction has on the mixing of fuel and air. As previously shown in Figure 14, only a small amount of water is produced for the $90 \%$ fuel-air equivalence case and is reflected in the lower combustion efficiency shown in Figure 21.

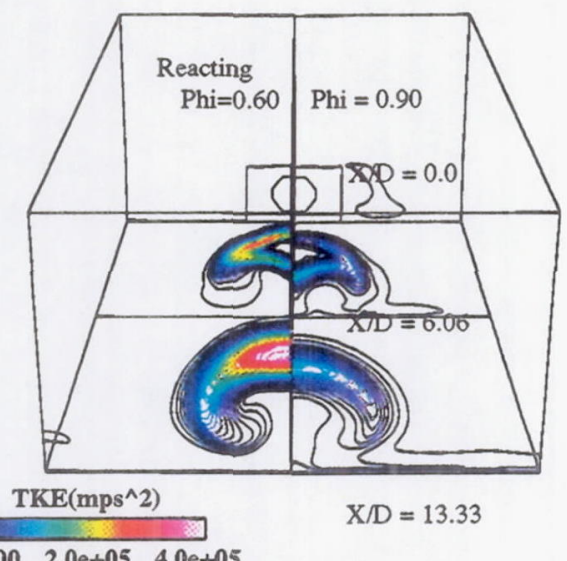

$0.0 \mathrm{e}+00 \quad 2.0 \mathrm{e}+05 \quad 4.0 \mathrm{e}+05$

Figure 20. Effects of Fuel-Air Equivalence Ratio on the Turbulent Kinetic Energy Prediction

It is also interesting to note that the mixing efficiency for this low combustion case closely matches the mixing efficiency obtained from the non-reacting solution. As the fuel-air equivalence ratio is reduced to $60 \%$, the influence of exothermic reaction on mixing increases, and higher mixing efficiency is then predicted. The increased combustion also leads to higher production of reacted products, such as water and hydroxyl, and leads to higher combustion efficiency. This behavior is consistent with observations made in numerical simulations of Givi ${ }^{29}$ where increased mixedness was observed with an increase in exothermic chemical reactions. The influence of the injector geometry on the fuel-air mixing is shown in Figure 21, where the fuel mass fraction contours generated by the swept ramp injector and the straight ramp injector are compared. This figure clearly shows the swept ramp injector generated peak fuel mass fraction decay behavior and fuel penetration characteristics that are much better than those generated by the straight ramp injector. This behavior further translates into higher mixing efficiencies shown in Figure 23.

Mixing and Combustion Emciencies

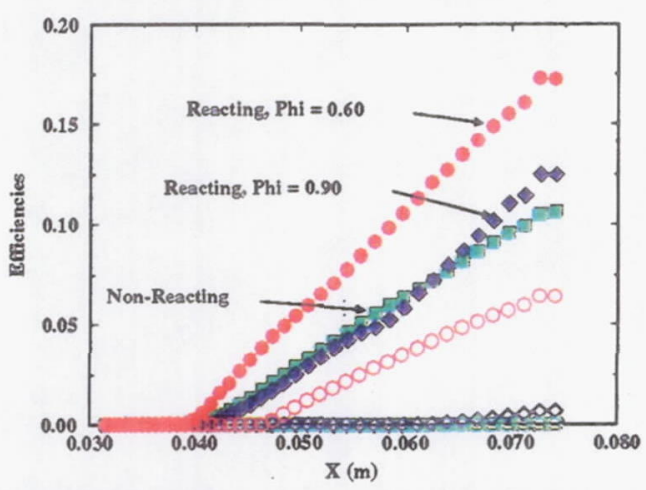

Figure 21. Non-dimensional mixing and combustion efficiency predictions 
Page intentionally left blank 


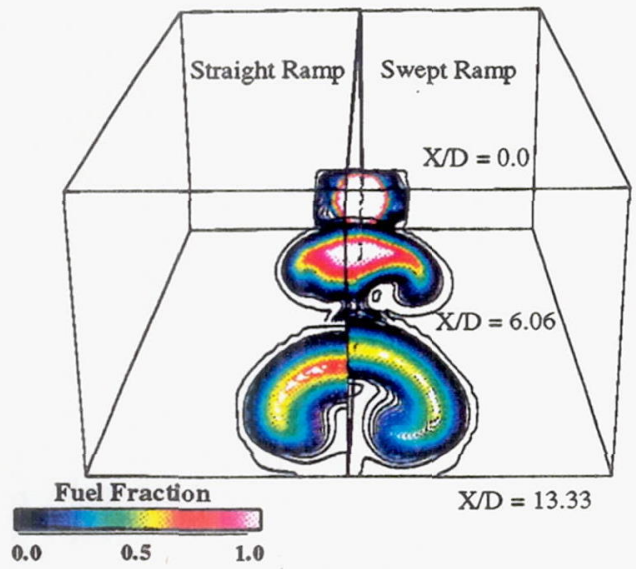

Figure 22. Comparison of a Swept Ramp injector and a Straight Ramp Injector Fuel Fraction Contours

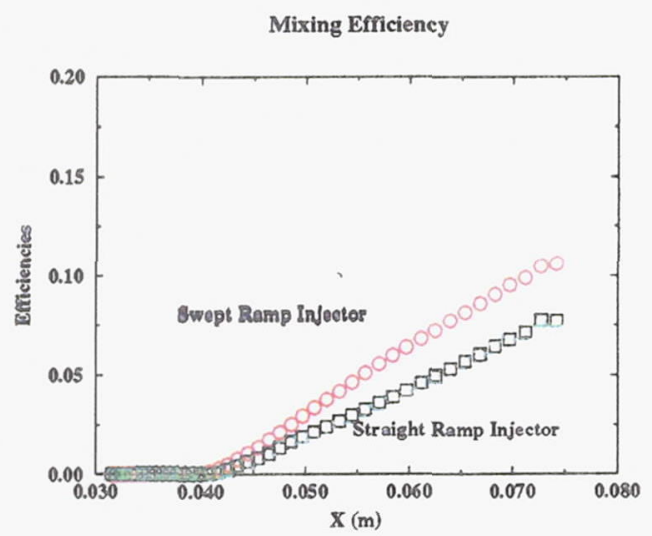

Figure 23. Prediction of Swept Ramp and Straight Ramp Injector Mixing Efficiency $\left(\bar{\phi}_{\mathrm{m}}\right)$

\section{Concluding Remarks}

A generalized flow solver using Lower-Upper diagonal decomposition techniques has been successfully coupled with three low-Reynolds number $\mathrm{k}-\varepsilon$ models for engineering analyses. A generalized solver for chemically reacting flows with a low-Reynolds number $\mathrm{k}-\varepsilon$ turbulence model has been developed. Preliminary comparisons of experimental data and computed solutions show reasonable agreement. Using a two equation model of turbulence requires only slightly more computational resources than using an algebraic model. However, the generalized formulation of the two-equation model provides flexibility and generality, and allows modeling of needed physics not possible with an algebraic model formulation. Several test cases have been used to illustrate the potential of the new CFD method in dealing with variation in fuel-air equivalence ratio and injector geometry. Additional analyses are needed to determine the effects of the low Reynolds model variations and the compressibility effects in injector/combustor problems. An alternate low-Reynolds number formulation that does not use the Van-Driest damping function should be further tested to avoided model formulation difficulties for complex combustor geometries.

\section{Acknowledgment}

This work was funded by Contract NAS 3-25266 monitored by Dr. D. R. Reddy and Dr. L. A. Povinelli. Extremely helpful suggestions of Dr. J. Shuen and other NASA LeRC personnel are gratefully acknowledged. The computations presented in this work were performed using resources from the LeRC-YMP and the C-90 at NAS.

\section{References}

1. Kumar A., Bushnell D. M., and Hussani M. Y., "Mixing Augmentation Technique for Hypervelocity Scramjets," AIAA P 87-1882, Jan 1987.

2. Brown G. L. and Roshko A., "On Density Effects and Large Structure in Turbulent Mixing Layer," Journal of Fluid Mechanics, V. 64, no. 4, 1974, pp775-816.

3. Drummond J. P., "Mixing Enhancement of Reacting Parallel Fuel Jets in a Supersonic Flow Field," Proceeding of 4th Int. Sym. on CFD, UC at Davis, Sept. 1991, pp 288-295.

4. Rao G. V. and Hieba A. A., "Use of Secondary Flows for Rapid Mixing in SCRAM-jet Combustors," AGRAD Conference Proceeding No. 479, Dec. 1990.

5. Povinelli L. A. and Ehlers R. C., "Swirling Base Injection for Supersonic Combustion Ramjets," AIAA J., Vol. 10, No. 9, Sept. 1972, pp 1243-1244.

6. Gutmark E., Shadow K. C., and Wilson K. J. "Non-circular Jet Dynamics in Supersonic Combustion," J. of Prop and Power., Vol. 5 No. 5, Sept. 1989, pp 529-533.

7. Drummond J. P., Carpenter M. H., Riggins D. W. and, Adams M. S., "Mixing Enhancement in a Supersonic Combustor," AIAA P 89.2794, July 1989.

8. Marble F. E., Hendricks G. J., and Zukoski E. E., "Progress Towards Shock Enhancement of Supersonic Combustion Process," AIAA P 87-1880, June 1987.

9. Patel V. C., Rodi W., and Scheuerer G., "Turbulence Models for Near-Wall and Low Reynolds Number Flows: A Review," AIAA J., Vol. 23, No. 9, 1985, pp.1308-1319. 10. Lee J., "Numerical Study of Mixing in Supersonic Combustors with Hypermixing Injectors," AIAA P 930215, AIAA J of Prop and Power, Vol 10, No. 3, pp 297. 304.

11. Coakley T. J., and Huang, P. G., "Turbulence Modelling for High Speed Flows," AIAA P 92-0436, Jan 1992.

12. Lee J., Taulbee D. B., and Holden M. S., "Study of Turbulence on Supersonic Compression Surface using Reynolds Stress Model," AIAA J. Vol. 30, No. 7, July 1992, pp 1738-1746.

13. Wilcox D., "Progress in Hypersonic Turbulence Modelling," AIAA P 91-17854, June 1991.

14. Favre A., "Equations of Compressible Turbulent Gases, General Formulation," Journal of Mechanics, Vol. 4, 1965.

15. Yu S.T., Tsai Y. L., and Shuen J. S., "Three Dimensional Calculation of Supersonic Reacting Flow using LU Scheme," AIAA P 89-8910, Jan 1989

16. Yoon S. and Jameson A., "Lower-Upper Symmetric Gauss-Seidel Method for the Euler and Navier-Stokes Equations," AIAA J. Vol. 26, No. 12, pp 1025-1026. 
Page intentionally left blank 
17. Shuen J. S. and Yoon S., "Numerical Study of Chemically Reacting Flows using LU-SSOR Scheme," AIAA J. Vol. 27, No. 12 , pp 1752-1760.

18. Lee J., "Analysis of Supersonic Flows with Low-Reynolds Number Compressible Two-Equation Turbulence Models using LU Finite Volume Numerical Techniques," AIAA P 94-0193, Jan 1994.

19. Launder B. E. and Sharma, "Application of Energy-Dissipation Model of Turbulence to the Calculation of Flow near a Spinning Disk," Letters in Heat and Mass Transfer, Vol 1, 1974, pp131-138.

20. Chien K.Y., "Prediction of Channel and Boundary-Layer Flows with a Low-Reynolds Number Turbulence Model," AIAA J., Vol. 20, No. 1, 1982, pp 33-38.

21. Shih T. H. and Lumley J., "Kolmogorov Behavior of Near-Wall Turbulence and Its Applications in Turbulence Modelling," NASA TM 105663, 1992.

22. Gordon S. and McBride B. J., "Computer Program for the Calculation of Complex Equilibrium Composition, Rocket Performance, Incident and Reflected Shocks and ChapmanJouguest Detonation," NASA SP-273.

23. Kanury M., Introduction to Combustion Phenomena, Gordon and Breach, c 1977.

24. Huang P. G., and Coakley, T. J., "An Implicit NavierStokes Code for Turbulent Flow Modeling," AIAA P 920547, Jan. 1992.

25. Givi P., Steinburg C., and Drummond P., "Effects of Compressibility and Heat Release in a High Speed Reacting Mixing-Layer," J. of Combustion Science and Technology, Vol 78, Nov 1991, pp3 3-68.

26. Yungster S., "Numerical Study of Shock-Wave/BoundaryLayer Interactions in Pre-mixed Combustible Gases," AIAA J. Vol. 30, No. 10, Oct. 1993.

27. Hartfield R., Hollo S., and McDaniel J., "Experimental Investigation of a Supersonic Swept Ramp Injector Using Laser-Induced Iodine Fluorescence, “ AIAA P 90-1518, June 1990.
28. Northam B. G., Greenberg I. and Byington C.S., "Evaluation of Parallel Injector Configurations for Supersonic Combustion," AIAA P 89-2525, July 1989.

29. McDaniel J., Fletcher D., Hartfield R. and Hollo S., "Staged Transverse Injection into Mach 2 Flow Behind a Rearward-Facing Step: A 3-D Compressible Test Case for Hypersonic Combutor," AIAA P 91-5071, Dec 1991.

30. Riggins D. W and McClinton C. E. "A Computational Investigation of Flow Losses in a Supersonic Combustor," AIAA P 90-2093, June 1990.

\begin{tabular}{|l|l|l|l|}
\hline Species & \multicolumn{1}{|c|}{$\sigma\left({ }^{0} \mathrm{~A}\right)$} & \multicolumn{1}{|c|}{$\mathrm{T}_{\varepsilon}\left({ }^{\mathrm{K}}\right)$} & $\mathrm{h}_{\mathrm{oi}}(\mathrm{J} / \mathrm{Kg})$ \\
\hline $\mathrm{H}_{2}$ & 2.827 & 59.7 & 0 \\
\hline $\mathrm{O}_{2}$ & 3.467 & 106.7 & 0 \\
\hline $\mathrm{OH}$ & 3.148 & 330. & $2.29 \times 10^{6}$ \\
\hline $\mathrm{H}_{2} \mathrm{O}$ & 2.641 & 809.1 & $-1.34 \times 10^{7}$ \\
\hline $\mathrm{H}$ & 2.827 & 59.7 & $2.162 \times 10^{8}$ \\
\hline $\mathrm{O}$ & 3.467 & 106.7 & $1.557 \times 10^{7}$ \\
\hline $\mathrm{HO}_{2}$ & 3.467 & 106.7 & $6.338 \times 10^{4}$ \\
\hline $\mathrm{H}_{2} \mathrm{O}_{2}$ & 2.641 & 809.1 & $-4.007 \times 10^{6}$ \\
\hline $\mathrm{N}_{2}$ & 3.798 & 71.4 & 0 \\
\hline
\end{tabular}

Table 2: Chemical Species Property

\begin{tabular}{|c|c|c|c|c|c|}
\hline $\begin{array}{l}\text { Comb } \\
\text { Parameter }\end{array}$ & Test Section & $\begin{array}{l}\text { Injector } \\
\text { Parameter }\end{array}$ & Hartfield & $\begin{array}{l}\text { Injector } \\
\text { Parameter }\end{array}$ & Test Case \\
\hline Width & $30.5 \mathrm{~mm}$ & Height $(H)$ & $4.90 \mathrm{~mm}$ & Height(H) & $4.90 \mathrm{~mm}$ \\
\hline Height & $18.1 \mathrm{~mm}$ & Diameter (D) & $3.30 \mathrm{~mm}$ & Diameter (D) & $3.30 \mathrm{~mm}$ \\
\hline $\mathrm{M}_{\mathrm{f}}$ & 2.0 & $\mathrm{M}_{\mathrm{inj}}$ & 1.7 & $\mathrm{M}_{\mathrm{inj}}$ & 1.7 \\
\hline $\begin{array}{l}\text { No. cells } \\
\text { (No.Blks) }\end{array}$ & $220,563(3)$ & $P_{f-t \alpha}$ & $262 \mathrm{Kpa}$ & $P_{f-t \alpha}$ & $790 \mathrm{Kpa}$ \\
\hline Block 1 & $45 \times 45 \times 45$ & $T_{i n j-t \alpha}$ & $300^{\circ} \mathrm{K}$ & $T_{f-t o t}$ & $1843^{\circ} \mathrm{K}$ \\
\hline Block 2 & $43 \times 27 \times 33$ & $P_{i n j-\alpha}$ & $252 \mathrm{Kpa}$ & $P_{\text {inj-to }}$ & $1547.6 \mathrm{Kpa}$ \\
\hline \multirow[t]{3}{*}{ Block 3} & $45 \times 45 \times 45$ & $T_{i n j-1 \alpha}$ & $300^{\circ} \mathrm{K}$ & $T_{\text {inj-tot }}$ & $\begin{array}{l}407^{\circ} \mathrm{K}(\bar{\phi}=.90) \\
893^{\circ} \mathrm{K}(\bar{\phi}=.60)\end{array}$ \\
\hline & & MFlow $_{f}$ & $.086 \mathrm{Kg} / \mathrm{s}$ & MFlow $_{\mathrm{f}}$ & $\begin{array}{l}.126 \mathrm{Kg} / \mathrm{s} \\
\text { (total) }\end{array}$ \\
\hline & & MFlow $_{\text {inj }}$ & $1.49 \mathrm{~g} / \mathrm{s}$ & MFlow $_{\text {inj }}$ & $\begin{array}{l}2.56 \mathrm{~g} / \mathrm{s} \\
1.73 \mathrm{~g} / \mathrm{s}\end{array}$ \\
\hline CPU(Cray) & $\begin{array}{l}1.7 \sim 3.1 \times 10^{-4} \\
\mathrm{sec} / \text { (iter-cell) }\end{array}$ & $\begin{array}{l}\text { Mem. Req'd } \\
\text { (Cray) }\end{array}$ & $\begin{array}{l}13 \mathrm{MW} \\
\text { (2species) }\end{array}$ & $\begin{array}{l}\text { Mem. Req'd } \\
\text { (Cray) }\end{array}$ & $\begin{array}{l}17 \text { MW (9 spe- } \\
\text { cies) }\end{array}$ \\
\hline
\end{tabular}

Table 3: Summary of combustor performance 


\begin{tabular}{|c|c|c|c|c|c|c|}
\hline Reactions & $\underset{\mathrm{sec})}{\mathrm{A}_{\mathbf{N}}\left(\mathrm{m}^{3} / \mathrm{kmol}-\right.}$ & $\begin{array}{c}A_{b}\left(\mathrm{~m}^{3} / \mathrm{kmol}-\right. \\
\mathrm{sec})\end{array}$ & $-E_{2} / R_{a}\left({ }^{0}\right)$ & $-E_{2_{b}} / R_{u}\left({ }^{0} K\right)$ & $\alpha_{1}$ & $\alpha_{b}$ \\
\hline $\mathrm{H}_{2}+\mathrm{OH} \leftrightarrow \mathrm{H}_{2} \mathrm{O}+\mathrm{H}$ & $4.74 \times 10^{10}$ & $2.03 \times 10^{12}$ & -3068.95 & -10985.2 & 0.0 & -.274 \\
\hline $\mathrm{O}_{2}+\mathrm{H} \ll \rightarrow \mathrm{OH}+\mathrm{O}$ & $1.85 \times 10^{11}$ & $4.50 \times 10^{8}$ & -8253.65 & 412.94 & 0.0 & .410 \\
\hline $\mathrm{H}_{2}+\mathrm{O} \ll \mathrm{OH}+\mathrm{H}$ & $4.20 \times 10^{11}$ & $2.28 \times 10^{11}$ & -6919.98 & -5998.66 & 0.0 & -.026 \\
\hline $\mathrm{O}_{2}+\mathrm{H} \leftrightarrow \mathrm{HO}_{2}$ & $2.20 \times 10^{11}$ & $5.10 \times 10^{13}$ & 503.27 & -25765.13 & 0.0 & -.424 \\
\hline $\mathrm{H}_{2}+\mathrm{M}<-\mathrm{H}+\mathrm{H}$ & $2.20 \times 10^{11}$ & $4.38 \times 10^{7}$ & -48314.04 & 4166.86 & 0.0 & .032 \\
\hline $\mathrm{O}_{2}+\mathrm{M} \leftrightarrow \mathrm{O}+\mathrm{O}$ & $1.80 \times 10^{15}$ & $1.517 \times 10^{9}$ & -59396.07 & 840.33 & -1 & -.525 \\
\hline $\mathrm{H}+\mathrm{HO}_{2} \ll-\mathrm{H}_{2}+\mathrm{O}_{2}$ & $1.30 \times 10^{11}$ & $1.275 \times 10^{10}$ & -1509.81 & 27672.11 & 0.0 & .427 \\
\hline $\mathrm{H}_{2} \mathrm{O}+\mathrm{M} \ll-\mathrm{OH}+\mathrm{H}$ & $1.30 \times 10^{12}$ & $5.736 \times 10^{6}$ & -52913.94 & 7491.96 & 0.0 & .313 \\
\hline $\mathrm{H}_{2} \mathrm{O}+\mathrm{O} \ll 2 \mathrm{OH}$ & $6.80 \times 10^{10}$ & $8.613 \times 10^{8}$ & -9242.58 & -404.79 & 0.0 & .250 \\
\hline $\mathrm{O}+\mathrm{HO}_{2} \ll \mathrm{O}_{2}+\mathrm{OH}$ & $5.00 \times 10^{10}$ & $2.650 \times 10^{9}$ & -503.27 & -25743.37 & 0.0 & .403 \\
\hline $\mathrm{H}+\mathrm{HO}_{2} \ll 2 \mathrm{OH}$ & $2.04 \times 10^{11}$ & $2.760 \times 10^{7}$ & -538.50 & -17119.5 & 0.0 & .808 \\
\hline $\mathrm{OH}+\mathrm{HO}_{2}<->\mathrm{O}+\mathrm{H}_{2} \mathrm{O}$ & $8.00 \times 10^{9}$ & $4.05 \times 10^{10}$ & -1499.75 & -35609.15 & 0.0 & .130 \\
\hline $\mathrm{H}_{2}+\mathrm{H}_{2} \mathrm{O}_{2} \leftrightarrow \mathrm{H}_{2} \mathrm{O}+\mathrm{HO}_{2}$ & $7.91 \times 10^{9}$ & $5.07 \times 10^{12}$ & -12581.78 & -3160.89 & 0.0 & .412 \\
\hline $\mathrm{OH}+\mathrm{H}_{2} \mathrm{O}_{2} \ll \mathrm{H}_{2} \mathrm{O}+\mathrm{H}_{2} \mathrm{O}_{2}$ & $6.10 \times 10^{9}$ & $3.761 \times 10^{9}$ & -719.68 & -18043.56 & 0.0 & .146 \\
\hline $2 \mathrm{HO}_{2}+\mathrm{M} \leftrightarrow \mathrm{O}_{2}+\mathrm{H}_{2} \mathrm{O}_{2}$ & $1.80 \times 10^{9}$ & $1.085 \times 10^{10}$ & 0.0 & -16734.1 & 0.0 & .021 \\
\hline $\mathrm{H}+\mathrm{H}_{2} \mathrm{O}_{2} \ll \mathrm{OH}+\mathrm{H}_{2} \mathrm{O}$ & $7.80 \times 10^{8}$ & $1.042 \times 10^{5}$ & 0.0 & -33982.3 & 0.0 & .899 \\
\hline $\mathrm{H}_{2} \mathrm{O}_{2}+\mathrm{M} \ll 2 \mathrm{OH}$ & $1.44 \times 10^{14}$ & $8.487 \times 10^{4}$ & -22903.88 & 3519.13 & 0.0 & 1.212 \\
\hline $\mathrm{H}+\mathrm{O} \Leftrightarrow \mathrm{OH}+\mathrm{M}$ & $7.10 \times 10^{12}$ & $2.106 \times 10^{16}$ & 0.0 & -51513.5 & -1 & 1.067 \\
\hline
\end{tabular}

Table 4: Laminar Reaction Rate Constants 
Public reporting burden for this collection of information is estimated to average 1 hour per response, including the time for reviewing instructions, searching existing data sources, gathering and maintaining the data needed, and completing and reviewing the collection of information. Send comments regarding this burden estimate or any other aspect of this gathion of information in Davis Highway, Suite 1204, Arlington, VA 22202-4302, and to the Office of Management and Budget, Paperwork Reduction Project (0704-0188), Washington, DC 20503.

\begin{tabular}{|l|l|l|}
\hline 1. AGENCY USE ONLY (Leave blank) & $\begin{array}{r}\text { 2. REPORT DATE } \\
\text { December } 1994\end{array}$ & $\begin{array}{r}\text { 3. REPORT TYPE AND DATES COVERED } \\
\text { Final Contractor Report }\end{array}$ \\
\hline
\end{tabular}

4. TITLE AND SUBTITLE

5. FUNDING NUMBERS

An Application of a Two-Equation Model of Turbulence to Three Dimensional Chemically Reacting Flows

6. AUTHOR(S)

WU-505-62-52

C-NAS3-27186

J. Lee

7. PERFORMING ORGANIZATION NAME(S) AND ADDRESS(ES)

NYMA, Inc.

Engineering Services Division

2001 Aerospace Parkway

Brook Park, Ohio 44142

8. PERFORMING ORGANIZATION

REPORT NUMBER

E-9278

9. SPONSORING/MONITORING AGENCY NAME(S) AND ADDRESS(ES)

National Aeronautics and Space Administration

Lewis Research Center

Cleveland, Ohio 44135-3191

AIAA-95-0734

\section{SUPPLEMENTARY NOTES}

Prepared for the 33rd Aerospace Sciences Meeting and Exhibit sponsored by the American Institute of Aeronautics and Astronautics, Reno, Nevada, January 9-12, 1995. Project Manager, D.R. Reddy, Internal Fluid Mechanics Division, NASA Lewis Research Center, organization code 2610, (216) 433-8133.

12a. DISTRIBUTION/AVAILABILITY STATEMENT

12b. DISTRIBUTION CODE

Unclassified -Unlimited

Subject Category 34

This publication is available from the NASA Center for Aerospace Information, (301) 621-0390.

13. ABSTRACT (Maximum 200 words)

A numerical study of three dimensional chemically reacting and non-reacting flowfields is conducted using a twoequation model of turbulence. A generalized flow solver using an implicit Lower-Upper (LU) diagonal decomposition numerical technique and finite-rate chemistry has been coupled with a low-Reynolds number two-equation model of turbulence. This flow solver is then used to study chemically reacting turbulent supersonic flows inside combustors with synergetic fuel injectors. The reacting and non-reacting turbulent combustor solutions obtained are compared with zeroequation turbulence model solutions and with available experimental data. The hydrogen-air chemistry is modeled using a nine-species/eighteen-reaction model. A low-Reynolds number $k-\varepsilon$ model was used to model the effect of turbulence because, in general, the low-Reynolds number $\mathrm{k}-\varepsilon$ models are easier to numerically implement and are far more general than algebraic models. However, low-Reynolds number $k-\varepsilon$ models require a much finer near-wall grid resolution than high-Reynolds number models to accurately resolve the near-wall physics. This is especially true in complex flow fields, where the stiff nature of the near-wall turbulence must be resolved. Therefore, the limitations imposed by the near-wall characteristics and compressible model corrections need to be evaluated further. The gradient-diffusion hypothesis is used to model the effects of turbulence on the mass diffusion process. The influence of this low-Reynolds number turbulence model on the reacting flowfield predictions was studied parametrically.

14. SUBJECT TERMS

Two-equation turbulence model; Turbulent chemically reacting flows; Supersonic; Hypersonic; Combustor; Injector; Hydrogen

17. SECURITY CLASSIFICATION OF REPORT Unclassified

18. SECURTY CLASSIFICATION
OF THIS PAGE
Unclassified

Unclassified
19. SECURITY CLASSIFICATION OF ABSTRACT

Unclassified 